\title{
Old habits die hard: An uphill struggle against rules without reason in mathematics teacher education
}

\author{
Niamh O'Meara ${ }^{1}$, Olivia Fitzmaurice ${ }^{2}$ and Patrick Johnson ${ }^{2}$ \\ ${ }^{1}$ EPI•STEM, University of Limerick, Limerick, Ireland \\ ${ }^{2}$ Department of Mathematics and Statistics, University of Limerick, Limerick, Ireland \\ For correspondence: niamh.omeara@ul.ie
}

\begin{abstract}
Mathematics teacher educators in the University of Limerick became aware of a lack of conceptual understanding of key mathematics concepts of prospective secondary mathematics teachers through observation on teaching placement and in pedagogy lectures. A pilot study to enhance the conceptual understanding of prospective teachers was carried out with one undergraduate class in 2009/10 and a longer more in-depth programme was offered to all prospective mathematics teachers in the academic year 2011/12. The intervention was designed to get prospective mathematics teachers 'thinking' about mathematics topics they have so far taken for granted and hence better prepare them for classroom practice. This retrospective study divulges a number of observations which emerged, the main one being how rote learning and an emphasis on procedural skills at the expense of conceptual understanding results in a cycle of ineffective teaching which is difficult to break.
\end{abstract}

Keywords: conceptual understanding, mathematics, teaching, learning.

\section{Context of the Study}

Teaching is an excruciatingly difficult job to do well (Schoenfeld, 2009, p. 215).

It is now well documented that students leave second level education and arrive at university with serious gaps in their knowledge (Gill et al., 2010; Hourigan \& O'Donoghue, 2007; Gill, 2006; The Engineering Council, 2000; O'Donoghue, 1999; Crowther et al., 1997; IMA, 1995). It seems that students nowadays lack fluency and accuracy in manipulating basic arithmetic and algebraic expressions (The Engineering Council, 2000; O'Donoghue, 1999; Crowther et al., 1997; IMA, 1995; LMS, 1995). In the studies examined, the spotlight is on student deficiencies, and the mathematics education students receive at second level is one contributing factor.

Students get a very formal notion of mathematics during their primary and second level years at school. They tend to have a very poor background in solving problems using the mathematics they have 'learned' at second level and as has been reported throughout the UK (IMA, 1995; LMS, 1995) and Ireland (Gill, 2006; O'Donoghue, 1999), their mathematical knowledge is often lacking. Murphy (2002) investigated the problem of mathematical under-preparedness in third level education, looking at the second level experience as a possible contributing factor. She used Brousseau's (1997) concept of Didactical contract (the unwritten contract between a teacher and student) as a theoretical framework. She reported that Irish second level students' experience of mathematics teaching thus far in their mathematical lives is their teacher standing at the front of the class, telling them what mathematics they need to know, how they need to approach the subject to pass their examinations and providing countless repetitive examples to practice (Murphy, 2002). Students do not contest this practice. The didactical contract (Brousseau, 1997) can be very narrowly focused as a result and can 
lead to negative outcomes such as poor motivation, lack of understanding and an inability to apply mathematics to solve problems. This view is supported by Mirirai et al. (2012) and Stylianides \& Stylianides (2007) who state that the barriers that students encounter in mathematics are either inbuilt in the topic itself or are down to the teaching knowledge and methodologies of their teacher. Thus the learners' understanding of mathematics and their ability to apply their mathematics knowledge to solve problems are all fashioned by the teaching they experience at school (Mirirai et al., 2012).The influence of the second level mathematics teacher therefore cannot be overestimated. Unfortunately, teachers tend to promote procedural understanding at the expense of conceptual understanding of knowledge (Schoenfeld, 1988; Nardi \& Stweart, 2003). This type of emphasis makes mathematical concepts irrelevant and abstract and ensures that students will be forced to rely on procedures themselves, thus having superficial understanding of key concepts (Mirirai et al., 2012; Carpenter, Fennema \& Romerg, 1993). This was evidenced in the Chief Examiner's Report on Leaving Certificate ${ }^{1}$ mathematics in Ireland (State Examinations Commission, 2005) when they reported that "... candidates' conceptual understanding of the mathematics they have studied is inferior to that which one would hope for and expect at this level. Whereas procedural competence continues to be adequate, any question that requires the candidates to display a good understanding of the concepts underlying these procedures causes unwarranted levels of difficulty." (p.72)

These findings were echoed in the TIMSS Report (1995) which found that almost 70\% of second and third year students (13 - 15 year olds) in Ireland were exposed to teachers who felt it was very important for students to remember formulae and procedures in order to succeed in mathematics. Of the 45 countries involved in this study only one country, Kuwait, reported a higher percentage of students exposed to such teachers. In contrast, only $20 \%$ of students were taught by teachers who felt that it was important to promote an understanding of the usefulness of mathematics, the lowest percentage among the 45 countries in the study. Furthermore and indeed supporting Murphy's (2002) findings, Mirirai et al. (2012) suggest that the contention that practice makes perfect is prevalent in many classrooms as teachers believe that giving several completed examples and having students to follow step by step procedures will enhance students' problem solving capabilities, with the result that many students attain a poor understanding of concepts. Mirirai at al's (2012) study displayed evidence that second level mathematics teachers tend to use traditional methods of teaching which are "anchored on practice of routine problem tasks, exemplification (teaching by giving examples), drill and teaching of rules and algorithms in the teaching of fractions" (p.90). Doyle (1978) suggests that mathematics is trivialised when it is presented to students in this manner, nothing more than a set of exercises that can be solved out of context in a series of finite steps, without requiring any understanding of the content. Stacey (2010) refers to this as the "shallow teaching syndrome" (p. 7) where mathematical reasoning and connections are absent in classroom practice and attention to routine problems and skills is dominant.

This is not to say that the teaching of procedures is not important. No one doubts the importance of proficiency in mathematics for learning of substance to occur (Clarke, 2010). However, procedural knowledge alone does not automatically ensure conceptual understanding. True mathematical understanding involves more than mere symbol manipulation (Schoenfeld, 1988). If a teacher relies on rules alone, students are denied the opportunity to construct a conceptual base to build on and as a result students graduate from second level perceiving mathematics as a set of rules to be learned off and practised (Crawford et al., 1998). Mirirai et al. (2012) maintain that only when rules are taught relationally will they facilitate conceptualisation. If procedural knowledge is the sum total of a person's wisdom, it will be impossible for them to reconstruct a forgotten procedure (Schwartz, 2008).

${ }^{1}$ The Leaving Certificate examination is the school leaving state examination in Ireland taken in at least 6 subjects including Mathematics which is compulsory. 
Students must be given opportunities to think mathematically as well as gain skill proficiency (Schoenfeld, 2009). In fact only when you marry procedural competence with conceptual understanding do you guarantee mathematical understanding (Star, 2000; Stylianides \& Stylianides, 2007). Certainly, a competent mathematics teacher needs both procedural and conceptual understanding to teach effectively (Ma, 1999).

Since teachers have a tendency to promote procedural understanding at the expense of conceptual understanding, it is no surprise therefore that students often demonstrate more procedural skill than conceptual understanding (Chief Examiner's Report, 2005; Conway and Sloane, 2005; TIMSS, 1995; Yin, 1994). Perhaps part of the problem is the way in which mathematics is viewed. According to Ernest (2010) it is frequently seen as 'a non-creative and mechanical subject' (p. 23). Problem solving is often encouraged, but is usually presented as a set of routine problems (Ernest, 2010). The result of this is that students who are dextrous in algebraic manipulations or application of formulae are often unable to apply their mathematical skills to real situations or indeed to interpret their answer in context (Schoenfeld, 1988). This is a shame as according to Pegg (2010) higher order skills only commence at the level where students demonstrate the ability to use knowledge in unfamiliar situations. Here students demonstrate the understanding necessary to solve problems without relying on a series of steps learned by rote. If students are not facilitated to reach this level they gain a very disjointed sense of mathematics as they will fail to realise the connections and underlying concepts (Schoenfeld, 1988). According to Schoenfeld (1988) an inability to apply procedural skills to solve real problems 'constitutes a dramatic failure of instruction' (p.7).

\section{The Influence of the 'Exam'}

The dangers of an examination led system were relayed by Faulkner (2012), Gill (2006) and O'Donoghue (1999) in an Irish setting while similar findings were reported internationally by Nisbet (1994) and Hagan (2005). Back in 1988, Schoenfeld reported on the risks of narrow assessments of competency. According to Star (2000), knowledge of concepts is often assessed verbally and through a series of activities while procedural knowledge is assessed uni-dimensionally and non-verbally by the correct completion of some procedure. It is only the latter which is enforced in the majority of schools. While second level mathematics curricula worldwide have moved towards promoting real life applications and new teaching methodologies, they are still, in the main assessed by means of a $100 \%$ examination. Such systems put pressure on teachers to adopt 'teach to the exam' methodologies where points/grades are more important than conceptual understanding. 'Teaching to the exam' means 'getting the work done' is the main objective of the teacher. Any learning that occurs is a bonus (Schoenfeld, 1988, p. 8). This situation is not peculiar to Ireland, with reports of similar pressures on teachers in the US (Scheonfeld, 1988), the UK (Nardi \& Stewart, 2003), Australia (Stacey, 2010) and Zimbabwe (Mirirai et al., 2012). In Mirirai et al.'s (2012) study teachers blamed time restrictions, an exam driven curriculum and limited resources as reasons for neglecting to teach for understanding. Examination pressure and the time limitations that brings with it, at least in the teachers' eyes, leaves few opportunities to allow students to explore or think about mathematics or figure it out for themselves.

Standardised, predictable examinations encourage a focus on procedural rather than conceptual skills in the classrooms, as that is what is assessed and rewarded. Faulkner (2012) reported how examination papers can encourage rote learning as it is often sufficient to learn off the previous year's paper to pass an examination. Research indicates that many students can 'solve problems' without reading the accompanying text. The numbers provided are often sufficient to answer the problems posed. Schoenfeld (1988) reported how students often circle the figures in the text and read backwards as the crucial word is usually near the end. Such findings led Schoenfeld to report that while rote learning/procedural instruction can yield good examination results (due to the content being assessed and the repetitive nature of examinations) these good results come at the expense of 
deep mathematical understanding among students. Furthermore it was reported in Ireland that second level mathematics teachers often advise students 'whatever you do, don't read the question, if it's questions 5 part (a) just do...' (Brosnan, 2010). Until recently it was sufficient to revise the previous year's paper to get through an examination as the layout of the Leaving Certificate examination papers was always the same with the order of questions unchanging. This predictability has been eliminated with the introduction of a new paper format and attempts are being made to ask conceptual based questions rather than procedural. Teaching rules without reason will no longer be sufficient to get students through this examination.

\section{Prospective Teachers' Knowledge and Understanding}

There are serious issues with prospective teachers' mathematics knowledge that teacher education programs ought to address (Da Ponte \& Chapman, 2008). Research indicates that many prospective teachers lack conceptual understanding of the mathematics they will be required to teach when they qualify (Newton et al., 2012; Slattery and Gill-Fitzmaurice, 2012; Ball et al., 2005; Behr et al., 1997;). If prospective teachers have little more than a superficial understanding of the mathematics content and its application in real life or in other subject areas, this results in prospective teachers being insufficiently prepared intellectually or pedagogically to make mathematics relevant to students or to illustrate the connections and links within mathematics (Toumasis, 1992). When this occurs, mathematics is taught as a series of distinct blocks rather than as a unified series of concepts and skills.

If prospective teachers do not have the requisite knowledge and understanding to provide alternative paths to understanding, many of their future students will be left without understanding as a consequence (Graeber, 1999). Graeber (1999) implies that if prospective teachers are not aware of alternative solutions to a problem, students may be informed that their methods or ideas are wrong when in fact they are correct or vice versa.

Thompson (1992, p.127) states that 'What one considers to be desirable ways of teaching and learning mathematics is influenced by one's conceptions of mathematics'. If mathematics is viewed and presented as a series of rules and step by step algorithms out of context, with no room for problem solving, that is how one will be inclined to teach it. Conway and Sloane (2005) state that: "Students' poor levels of mathematical understanding are typified by concerns about schools' focus on procedural, routine, inflexible, abstract and inert knowledge rather than fostering students' capacity in conceptual problem focussed, practical and flexible use of mathematical knowledge" (p. 16). For teachers to be able to teach with an emphasis on conceptual understanding, they must have the conceptual underpinnings themselves (Schwartz, 2008). An emphasis on rules and step by step algorithms means that mathematics is often presented and hence viewed as a physical rather than an intellectual activity (Schoenfeld, 1988).

When students are taught concepts by a series of steps and rules, they are not afforded the opportunity to construct a conceptual foundation for understanding (Mirirai et al., 2012). Watson (2004) reports on the fact that teachers have a tendency to promote procedural understanding at the expense of conceptual understanding. This research is supported by the findings of Slattery \& GillFitzmaurice (2012), a study carried out on a sample of this cohort of prospective teachers to measure their conceptual understanding of fraction division. These prospective teachers had ( 2 months before completion of their undergraduate degree programme) at best a fragmented understanding of the concept of fractions, were unable to explain the invert and multiply rule and could not come up with any real life examples to represent a relatively straight forward problem related to the division of fractions. They relied on a series of 'rules without reason' to answer the questions posed. The outcome of the investigation was that these prospective teachers would have no choice but to rely on a series of learned algorithmic steps as they did not have the conceptual understanding necessary to 
teach for understanding. This supports the findings of Schoenfeld (1988) and the SEC (2005) who maintain that being able to correctly perform a series of step by step procedures does not automatically indicate conceptual understanding. Learning rules without reason results in superficial learning (Stylianides \& Stylianides, 2007).

\section{Impact of School Experience on Prospective Teachers Teaching}

Prospective teachers' practice is informed by their own schooling experiences. Consciously or subconsciously their impressions of how teachers and students are to perform get formed in this way and hence they are predisposed to end up teaching in the same manner (Kennedy, 1999). Time spent in mathematics classrooms as students, gives prospective teachers a specific 'apprenticeship of observation' (Lortie, 1975, p. 61) with the result being that teachers are highly likely to teach how they were taught (Kennedy, 1999, Hopper, 1999, Toumasis, 1992; Britzman, 1991, Lortie, 1975). If their teachers represented mathematics in a certain manner, they will tend to teach this way themselves (Kennedy, 1999). It is through this apprenticeship or 'frame of reference' (Kennedy, 1999) that prospective teachers develop their own conceptions about teaching and what constitutes good/bad practice (Toumasis, 1992). A teacher's perception of what effective teaching means depends on how they were taught (Hopper, 1999). This is no great surprise really as personal mathematics histories have been shown to impact significantly on the mathematics education of an individual (Daro, 2010).

Frames of reference are important guides for teachers. They enable teachers to interpret the situations that arise in their classrooms and provide them with ideas for how to respond to those situations. Kennedy's study (1999) suggests that although teachers may espouse ideas about teaching that deviate from the narrow prescriptive tradition, they are less likely to act on those espoused ideas (Kennedy, 1999). Frames of reference may be more of a hindrance than a help if prior experiences have been unsatisfactory (Kennedy, 1999; Hopper, 1999). According to Toumasis (1992) 'In all too many mathematics classrooms, the teacher is the authority, theorems are proved mechanically and learned by students by repeating the steps in excruciatingly fine detail' (p. 292). Little research has been published since Toumasis paper to convince one that much has changed.

Kennedy (1999) predicts that any sort of reform will fail if the success of it depends on the frames of reference prospective teachers carry with them. Prospective teachers, armed with bad vivid images to influence their practice are inclined to teach just as they were taught (Toumasis, 1992). Teacher educators expect prospective teachers to teach in a certain way which may be at odds with what they have observed in their 13 years at school (Kennedy, 1999). It is only possible to change the teaching practices of prospective teachers by rewiring their views on various classrooms situations and forcing them to think outside the box of how to respond rather than just using the methods of their former teachers (Kennedy, 1999).

\section{Methodology}

Observation of prospective teachers on school placements offered anecdotal evidence of superficial understanding of mathematics fundamentals which was impacting on their ability to teach conceptually thus forcing them to place an emphasis on procedures and rely on rules without reason in many cases. The mathematics teacher educators at the University of Limerick wanted to tackle the prevalence of procedural understanding and deepen the superficial understanding among prospective teachers through a series of 'Maths Thinking Classes'. The researchers sought to investigate if this intervention could impact on prospective teachers' mathematical understanding and their approaches to learning and teaching mathematics fundamentals. 
The following research questions allowed the authors to address these research aims:

- What impact does procedural teaching at second level have on prospective teachers' knowledge?

- What impact does procedural teaching at second level have on prospective teachers' teaching practice?

- Is it possible to break the cycle of procedural teaching and learning?

The 'Maths Thinking Classes' were designed to get these prospective teachers to 'think' about certain concepts that until now they have taken for granted e.g. why does a negative number multiplied by a negative number result in a positive number? Why do we invert and multiply when dividing fractions? What is $\pi$ ?. In the academic year $2011 / 12$ a series of 9 ( 2 hour voluntary) classes was held outside students' official timetable to discuss such mathematical concepts. The objectives of the classes were fourfold;

- To enhance content knowledge of prospective teachers (Holm \& Kajander, 2012; Toumasis, 1992)

- To provide an opportunity to do 'school maths' (Holm \& Kajander, 2012; Toumasis, 1992)

- To provide opportunities for mathematical thinking and reasoning (Schoenfeld, 1988; 2009)

- To provide a new frame of reference (Hopper, 1999; Kennedy; 1999; Toumasis, 1992)

\section{Data Collection and Analysis}

The classes were offered to all prospective mathematics teachers in the University of Limerick (with the exception of final year prospective teachers who were on school placement when the course was offered). At the beginning of the first class, the prospective teachers were presented with a number of simple teaching tasks. Each group were given time to discuss how they would teach their own particular concept before one member from each group approached the whiteboard and taught the idea as they would to a secondary school student. This session was recorded on video. The purpose of this class was to provide empirical rather than anecdotal evidence of the types of issues prospective teachers presented in terms of knowledge and its knock on effects on teaching strategies.

After this initial experiment students were then encouraged to 'think' about key concepts in mathematics and discuss in groups how they would teach key concepts to second level students, how they would explain 'rules' to students and how they would establish links between mathematical concepts. Feedback on each of the classes was received in the form of student evaluations sheets, facilitators' observation journals and a focus group of volunteers at the end of the year.

The data was collected in part to assess students' levels of satisfaction with the classes and to see how we could improve the classes in subsequent years. All data was analysed qualitatively through an iterative process which involved identifying relevant trends that appeared regularly and atypical responses were also noted. Three of the facilitators/researchers reviewed the data independently utilising a grounded theory approach (Glasser and Strauss, 1967), which supports the notion that theory emerges from the data and not vice versa. Initially emerging themes were identified and noted by the researchers individually. Common themes were then identified as nodes. Having completed this stage of the analysis, the same researchers reviewed the data again, using NVivo, to identify supporting statements from the participants relevant to each node. The resulting statements common to all three researchers are illustrated in the findings section.

A quantitative evaluation of the classes in terms of how they impacted on the participants' conceptual understanding or teaching methodologies was not possible for a number of reasons. As shown in Table 2, overleaf, the participants in this study were all at different stages of their teacher training while there was also a combination of undergraduate and postgraduate students. As a result all participants in the study were coming from different mathematical backgrounds and even had 
different mathematical experiences throughout the academic year. As a result there was no way to quantitatively assess whether or not this intervention explicitly impacted on their mathematical understanding.

\section{The Classes - Content and Delivery}

9 classes were held on the following topics: Indices, Logs, Fractions, Integers, Equations and Inequalities, Quadratic Equations, Formulae, Trigonometry and Statistics. The intention was to hold 20 classes (10 in each semester) but attendance dropped as the year progressed so only 9 classes were held. 3 facilitators attended each session and their role was to continuously ask questions, monitor discussions among students in the class and offer insights, advice and possible explanations when required. At the end of the classes the facilitators also led a whole class discussion whereby students got to share their ideas with their peers in the class and this allowed all students to develop further ideas in relation to the key concepts discussed in that class. All facilitators lecture Mathematics and/or mathematics pedagogy at this university and supervise teaching placement of prospective teachers.

\section{The Sample}

There are two types of pre-service mathematics teacher in the University of Limerick; undergraduates and graduate diploma students. The undergraduate degree is a 4 year programme. It is a concurrent model of teacher education which results in successful participants graduating as dual teachers of Physical Education and Mathematics. The modules that these students take throughout the programme are outlined in Table 1. Students on this programme are placed in schools on 'teaching practice' for a total of 16 weeks in their second and final year.

Table 1. Mathematical Background of Undergraduate Prospective Teachers

\begin{tabular}{ll}
\hline Semester 1 & Semester 2 \\
\hline Technological Mathematics 1 & Technological Mathematics 2 \\
Algebra 1 & Algebra 2 \\
Semester 3 & Semester 4 \\
Statistics and Probability & Mathematics Pedagogy 1 (4 weeks) \\
Mathematics Laboratory (Computer based module) & Teaching Practice (6 weeks) \\
\hline Semester 5 & Semester 6 \\
\hline Analysis & Mathematics Pedagogy 2 \\
Linear Algebra & History of Mathematics \\
Semester 7 & Semester 8 \\
Teaching Practice (10 weeks) & Group Theory \\
& Differential Equations. \\
\hline
\end{tabular}

The graduate diploma is a one year programme and entry is based on having achieved an honours primary degree with $30 \%$ minimum mathematics content. In the graduate diploma, students study Number Theory and Mathematics Pedagogy in the first semester and either Pure Mathematics or Mathematical Modelling (depending on whether their primary degree was applied or pure based) in the second semester.

As the classes were voluntary attendance varied from week to week but over the nine week course the classes were generally made up of third year PE and Mathematics students and Graduate Diploma in Mathematics students. Table 2, overleaf, shows the participants that attended each of the nine different classes. 
Table 2. Breakdown of Attendance by Year

\begin{tabular}{cccccc}
\hline $\begin{array}{c}\text { Class } \\
\text { Number }\end{array}$ & $1^{\text {st }}$ Year & $2^{\text {nd }}$ year & $3^{\text {rd }}$ Year & $4^{\text {th }}$ Year & Grad Dips \\
\hline 1 & 3 & 2 & 7 & 0 & 22 \\
2 & 0 & 0 & 6 & 0 & 19 \\
3 & 0 & 0 & 9 & 0 & 15 \\
4 & 0 & 0 & 8 & 0 & 15 \\
5 & 0 & 0 & 6 & 0 & 19 \\
6 & 0 & 0 & 5 & 0 & 19 \\
7 & 0 & 0 & 4 & 0 & 10 \\
8 & 0 & 0 & 4 & 2 & 0 \\
9 & 0 & 0 & 3 & 0 & 0 \\
\hline
\end{tabular}

\section{Findings}

To begin the authors will analyse the findings to emerge from the facilitators and participants' journals before discussing the findings recorded during the focus groups.

\section{Findings from Teaching Task}

The classes gave a deep insight into the misconceptions and superficial understanding many of our prospective teachers take with them from school. In the first session where students were asked to teach some mathematical topic on the whiteboard, it was clear that many of them relied excessively on procedures and rules and taught in the same way as their teachers. This was widely reported in the facilitator's journals (F1-F6):

'...there was an inclination to teach using rules without reason...'(Grad Dip Male) started by putting up the power rule for differentiation. Over reliance on rules and procedures for most of these teachers' (F1)

'During the video tasks there were a number of instances of superficial understanding of concepts. For example one student plotted points incorrectly and then simply subbed the numbers into the formula without any explanation. One group also solved an equation by "bringing across the 4 and changing the sign"' (F2)

Over reliance on the invert and multiply rule for division of fractions was also evident. One student was asked to teach $3 / 4 \div 1 / 2$. Multiplication was described as the 'absolute opposite of division' which was followed by 'so the opposite of $1 / 2$ is 2 obviously... flip the $1 / 2$ and it becomes 2 and $\div$ becomes $a x^{\prime}$. The mean of an array of numbers was another topic to be taught. The procedure of summing and dividing by the quantity of numbers was given without explanation. Addition of fractions was presented in a very mechanical fashion. 'What you do on the bottom, you do on the top' was how it was relayed to the group. The denominators were referred to as the 'bottom numbers' throughout the process. There was no mention of equivalent fractions or no diagrams or examples used.

One student was asked to solve the inequality ' $4-2 x>6$ '. He stated you 'bring across the 4 so it becomes -4 ', and also that 'in inequalities, when you divide across by minus, it changes the inequality'. Again, there was no attempt to explain the underlying concepts. One student demonstrated a good attempt to teach for understanding, using the analogy of two ladders propped against a wall. She asked her peers which ladder they would prefer to climb. She proceeded to explain why one had a sharper rise than the other and developed the formula to calculate a slope. It was clear this student had a good conceptual understanding herself and was able to teach and explain the concepts using a real example, rather than just presenting a formula in which to substitute values. 
When asked to differentiate a simple function, one mature student who had a number of years' experience teaching mathematics at second level, wrote up the differentiation rules before he started. He proceeded by saying 'how we are going to do this is using some simple rules...the first rule is when you differentiate a constant you get 0 , the second rule is....' The power rule was presented as a series of steps that demonstrated he did not fully understand the concept, as he told the group to 'multiply by what's in front of our term' rather than coefficient.

Formulae were presented without explanation; one student was asked to explain the distance formula ...she merely selected some coordinates and substituted in the values. Even the coordinates she selected $(1,2)$ and $(2,1)$ were ill chosen as they could cause confusion.

Students found it difficult to articulate what they meant and used incorrect vocabulary. When solving $3 x-2=7$, the student stated that 'we want to get $x$ without the 3 in front of it'. This could be very misleading in a classroom situation. Inequalities were introduced by saying 'it's called an inequality because of the > symbol'. No other explanation was given in terms of how it differs from an equation regarding range of solutions.

\section{Findings Recorded During the Intervention}

After the teaching task, students were given a sheet per class to explore and discuss in small groups and think about typical mathematical concepts that are generally taught procedurally. Students were asked to question 'why' and to consider

1. How would they introduce the concept to their class?

2. Where might their students have difficulty?

Throughout the intervention the level of conceptual understanding was a prominent theme and entries in the facilitators' journal demonstrated an overreliance on rules and procedures on the part of prospective teachers.

When asked to explain why $a^{0}=1$ one student said just put any number into your calculator, raise it to the power of zero and see how your answer is always 1.(F2)

I was surprised by the fact that a number of different students were not able to explain in simple terms what the square root of a number was. (F2)

$x^{0}=1$. The majority of groups really struggled here until they were prompted. Some I talked to said they always just thought it was a rule to learn off. (F3)

Common denominator was surprisingly routine for some. They didn't understand what they were doing. They just knew how to do it. (F4)

Dividing by a fraction is clearly something that they learned by rote. They could not state why you invert and multiply. They (many) used the example of dividing by $1 / 2$, how many halves are in 8 or whatever but could not transfer this to dividing by $3 / 7$ etc.(F1)

Prospective teachers also appeared to have limited knowledge in other domains. For example their knowledge of connections, which was identified as an important component of a mathematics teacher knowledge base by O'Meara et al. (2011), needed attention.

Many did not know how closely logs and indices were used.(F3)

In addition to this, another inter related knowledge domain required by mathematics teachers is a 
knowledge of applications. However a lack of appreciation or knowledge of real life examples among prospective teachers was also noted.

They were introduced to the topic through learning a set of rules and many struggled to think of alternative ways of introducing the topic and linking it to everyday life.(F3)

Real examples were few and far between outside of pizza and cake. They really needed to be probed to think outside of the box here.(F1)

Very few students could see where negative numbers are used in the real world except when talking about being in debt.(F2)

Despite the shortcomings in the knowledge base of these prospective teachers and the prevalence of procedural understanding at the cost of conceptual understanding among participants there was also some progress evident during the intervention. This progress was recognised by the facilitators and certain instances where students demonstrated conceptual understanding were highlighted in their journals.

There were many instances of learning/progression among participants... The rule $a^{0}=1$ proved difficult for most groups. However after some prompting they could make the connection and were surprised at how logical and basic this was. One participant noted that he "could not believe this was not explained in the textbooks." (F3)

(After the class) Students had a far greater understanding of what logs are, where they are used and particularly how the rules could be explained. Students also had better ideas and approaches on how to introduce logs to students for the first time.(F3)

Overall the facilitators' journals highlight the progression made by prospective teachers over the course of this intervention. This progression was also highlighted in the post intervention data collected by means of a focus group and post lesson evaluation sheets.

Evaluation of the Intervention (Focus Group Findings)

Having received feedback sheets from students throughout the programme and conducted two focus groups at the end, a number of themes emerged from the data. Each theme will be discussed in turn with supporting references from the participants.

1. An awareness by students that their knowledge is below what they thought

2. Enjoyment of classes - could aspects from this class be integrated into other modules?

3. A New Frame of Reference was provided by the facilitators

4. The potential positive impact these upskilling classes had on prospective mathematics teachers' teaching

An awareness by students that their knowledge is below what they thought

One of the first findings to emerge from the post intervention data was that the course highlighted to students the limited nature of their knowledge:

Rob: It's a good confidence builder as well. It's helped me understand some parts of maths that I wasn't really sure of. I'm a bit more confident now to go teaching in secondary schools.

Padraig: Well there was a few things you come across, you're like 'I thought I understood that' but it's totally different to what my understanding is. 
Brian: The module nearly justified itself in terms of our reactions to things, you know, so it was obvious to see that it was worthwhile from the fact that none of us, almost none of us, understood a lot of the meanings behind it.

Laura: I thought 'yeh I'd be able to explain that, that's fine' but when you actually do you're like 'no I don't know..how would you explain it?'

Diarmuid: I came into college even thinking I was pretty good at maths and kind of realised that ...I'm not.

Emma: Felt underprepared. I couldn't answer questions to the depth needed. Lacking knowledge as a teacher.

Students also became aware that how they were taught themselves and how they approached learning mathematics themselves was not necessarily the right way despite being high achievers in mathematics. They began to appreciate the need to move away from the procedural approach to teaching mathematics in order to foster deeper understanding among their students as the following extracts show:

Laura: yeh sometimes because you are coming from a system where it's been drilled into you, sometimes in the maths thinking class, you realise 'god that's been drilled into me, that I've just taken that as a given'..I surprised myself to think 'God I've never actually thought 'where did that come from?' because the whole way up it's been drilled in. 'How actually would I explain that to someone else?' I was surprised. I thought the (maths) thinking classes were really good for that.

Emma: (It was) taken for granted that rules had to be learned when in school, generally didn't ask questions.

Another instance when it became clear that the maths thinking classes had led to a shift in students' views in relation to the importance of conceptual understanding came when they discussed how an over reliance on rules without reason can be a bad thing.

Mairead: to be honest, half the stuff that we did in the maths thinking classes I just learned them off. Like the $\pi r^{2}$ we did the last day, the circle, you're not really thinking about it, it's just $\pi r^{2}$..that's the way it is. But when you think about it, we went through it, it actually made sense, it was really good.

Nichola: If someone asked 'why is that the formula?'....it used to be 'just because', because you didn't know the answer but you could actually, if you wanted to, go about explaining it or at least tell them where it derives from instead of just going 'ah that's just the way it is, you just have to learn it off'.

Ciara: Even deriving the minus b formula [Quadratic Formula], we did that for Leaving Cert, the proof is on the Leaving Cert. I just learned that off, it was a series of letters, I wrote one after the other and that was it. But (now) I actually understand what we are doing.

Gerard: I was basically doing everything we don't want students to do. Just learning it off and not understanding it.

This realisation that the way they were taught did not allow for them to develop a deep understanding of mathematics further highlighted to students the fact that their knowledge is below what it probably should be for a mathematics teacher: 
Diarmuid: I thought they were very good yeh. I did yeh...just to get us thinking about, get us thinking first of all thinking about where everything comes from like. Because even when we were doing them, I didn't know where some of them came from. We had to work together and figure it out ourselves and obviously think about how the students... think about how we could teach it to students as well like or explain it to them.

Philip: The logs (class) really sticks out in my mind ...I used not know anything about logs. I mean I didn't even know that they were related to indices when I was doing the leaving cert..... you always just take that for granted usually ... and you never actually ... you never realise that you actually understood it or you didn't understand it before you ever came to college.

Annette: Student teachers may think they know it all but they don't. If we want to change the way maths is taught they need to understand the maths themselves before teaching it to students. These classes are an opportunity to do that.

A New Frame of Reference was provided by the facilitators

Another important finding to emerge from the data collected from students was that this course allowed them to experience a new frame of reference.

Phillip: it's probably the only part of college where we are taught in the way we are being told to teach. You know we are always being told to be so interactive and have loads of problem solving, thinking and then we're just going into lectures and being given the knowledge ..one of the few things, examples of how we should be teaching,.. how we could have our classes... you know?... we need an example of it before we can really be expected to go in and do it ourselves.

The new frame of reference experienced by participants was appreciated by many and offered them ideas in relation to how they could approach their own classes in the future.

Ciara: (The structure of the class) worked to its advantage I think because people were just putting forward a load of ideas.

Padraig: It's more informal. You feel you can say whatever you want.

Brian: I think the fact that you were being contradicted helped an awful lot. Say, you'd say something and then (another facilitator) would say "Well actually...' so then we all kind of got thinking we can say whatever we want. Do you know, whereas so it wasn't the 4 or 5 (facilitators) that were always right and then all of us were coming up with our own little ideas and were always wrong..so that's not the way it turned out. That helped a lot.

Deirdre: Helpful; non-judgemental; approachable.

The Positive Impact of the New Frame of Reference

It was evident from the feedback received from participants that the classes and in particular the new frame of reference which these classes provided had impacted on their teaching (whilst they were on placement) and encouraged them to consider their future teaching practices.

Padraig: Just one more thing I'd say as well these classes were very good and I'd like to bring them to my own teaching ...just relating all the different parts of maths to each other. Teachers just isolate them... (to peer) was it your teacher that just isolated them?...I'd say most of our teachers did...just isolate the sections off.. like you talking about logs and indices and the relationships ...just really connecting things like as you go along. 
Gerard: (I) would not make the students learn them off by heart like I would have.

Brian: Just say if you take the example of the fractions class. There's so many different ways that you can actually come at fractions and the more ways that you have of explaining to the students, the more likely they are to pick it up because some of them will learn one thing and others will learn another even if, what was it?, the...the double negative, there was 3 or 4 different ways we came up with looking at that... and they should remember at least one.

Laura: And even simple things like one of the students I taught on teaching practice, the adding of two negatives,... do you know...they just couldn't get it. Because of the (maths) thinking class...rather than just saying 'that's the rule', I was able to come up with loads of examples ...em...practical examples... and it clicked with them so it was good.

Diarmuid: the way I'd approach teaching something like, say, just equations in algebra or something ... approach teaching it rather than just giving them the rule, say 'bringing across and change the sign' or whatever...that's just one example. The way I'd approach teaching things would be completely different now. Go for the real basis, conceptual understanding.

Kathy: I understand better now and am able to explain to students instead to telling them learn it off.

Annette: I really want my students to understand what they are doing and why. I now know new techniques.

The students stated that the classes gave them more confidence to go into the classroom and overall they felt that it did help them to develop knowledge necessary for teaching mathematics.

Rob: It's a good confidence builder aswell. It's helped me understand some parts of maths that I wasn't really sure of. I'm a bit more confident now to go teaching in secondary schools.

Gerard: it was good for the old confidence .... going out (on placement) I suppose I would have been sketchy enough if we had enough maths in us to go out and teach as it is

Simon: The circle and radian. That was one for me, do you know the way that each sector is the radian you work around and you get your one eighth radian at the end, or something, was one sixth of a radian or whatever it was. That was one probably, which explained what the radian was rather than just saying it's a figure, 57 degrees or whatever. You actually can see it.

Gavin: $x^{0}$. That's something I always took for granted...it's just 1 ...I never really thought about it or whatever. And then just to go through the explanation of it then was good. It was all the fundamentals that you take for granted.

\section{Discussion}

From the outset of this project the prevalence of rules without reason among the prospective teachers was discussed in the facilitators' journals. As highlighted previously these prospective teachers were unable to explain the rules and procedures used to solve mathematical problems and instead they demonstrated many of the characteristics that Sawx, Gearhart \& Nasir (2001) associate with procedural knowledge for teaching. For example those involved in the first lesson in this intervention, with the exception of the student who used a real life example to derive the formula for the slope of the line, demonstrated a knowledge of step by step algorithmic procedures and memorised facts without ever displaying a knowledge of the rich and connected nature of mathematics associated with meaningful or conceptual understanding. According to Sawx et al.. (2001) this indicates that, at 
the beginning of this intervention, at least, these teachers possessed instrumental knowledge of mathematics and this only allowed them to present the topic in a procedural manner.

This opening session was not the only time that these teachers demonstrated the limited nature of their conceptual knowledge. At different stages during this project subjects were cited as saying that they always thought the rules or procedures being discussed were items that needed to be learned off. However the authors do not believe that these prospective teachers can be blamed for possessing such notions. A central premise of a paper written by Ball \& Mc Diarmid (1990) was that teachers acquire the majority of their mathematical content knowledge during second level. However much research in the field has pointed to the procedural way in which mathematics is taught at second level and hence this approach is impacting on the levels of knowledge as well as the teaching practices of these prospective teachers. For example Nardi \& Stewart (2003) found that in order to prepare students for state examinations at second level many teachers encourage students to mimic the procedures and rules which they demonstrated without any explanation. Similarly Stacey (2010) found that 'shallow teaching syndrome' (p. 17) which was evident in many Australian classrooms was leading to mathematical reasoning being overlooked in the classroom. This procedural approach to teaching will not present students with the opportunity to develop deep understanding of mathematics in the institution where they acquire the majority of their mathematical knowledge and so it is unsurprising that these students demonstrated low levels of conceptual understanding in this study. Another finding from the work of Ball \& Mc Diarmid (1990) was that even at third level students have very little opportunity to develop their conceptual understanding. They state that "...most prospective teachers have few, if any opportunities in school, college, or the wider culture to come to understand the substance and nature of their subject matter or to develop dispositions that would enable them to teach in ways that their students, in turn can understand in meaningful, connected ways" (p. 2). Such findings further emphasise the fact that we cannot blame these students for the limited levels of conceptual knowledge that they displayed but instead we must focus on addressing the problem at second and third level, possibly by providing prospective teachers with a new frame of reference.

In addition to the poor level of relational knowledge demonstrated by prospective teachers in this study the facilitators' journals also suggested that their knowledge in other knowledge domains deemed necessary for mathematics teaching was also limited. At different stages during the intervention facilitators noted how students were unable to see the inter-related nature of mathematics or to highlight the applications of the subjects. This is in line with the findings of Boaler (1998) when she indicated that many students were able to learn mathematics for eleven years or more (as was the case with all subjects in this study) but are then incapable of using such mathematics outside of a school setting or in a context relevant to their everyday lives. This was certainly the case with subjects in this study as it was reported that many could not link basic topics such as fractions or negative numbers to meaningful real life situations. This will have a serious impact on their own teaching as without possessing such knowledge they will be unable to highlight the relevance or importance of mathematics to their own students. In addition to this students could not even link mathematical topics, such as logs and indices, to each other. However the authors are again reluctant to place the blame for this shortcoming with the students. In research carried out by O'Meara et al.. (2011) they found that practising teachers' collateral knowledge of applications and connections needed attention. These practising teachers were also never given the opportunity at third level or during continuous professional development programmes to develop this knowledge (as it was not deemed necessary for teaching the old curriculum) and so without ever having acquired such knowledge it was difficult for them to impart knowledge that they simply did not have to the subjects involved in this study. As a result of such findings it is now evident that more attention needs to be afforded to helping students develop a wide range of knowledge domains and maybe interventions or modules such as that trialled during this study will allow teacher educators to do just that. 
As well as facilitators highlighting the issues surrounding the knowledge base of these prospective teachers the researchers also found that this course actually helped prospective teachers to realise how little mathematics they knew. All prospective teachers involved in this study would have been high achievers at second level yet this course made them realise that they never fully understood many of the concepts which they had become familiar with and that they had practised endlessly up until this point. This is not a problem refined to subjects in this study and instead Ball (1990) believed that this was a problem facing mathematics educators around the globe. She asserted that success in mathematics at pre-tertiary level derives from memorising formulae and the repetitive practice of procedures and as a result despite students entering third level believing they are competent in mathematics and with the results at second level to prove it, it soon becomes evident that they do not understand the mathematics that they have studied. Therefore a benefit of this intervention was that it compelled students to analyse their own knowledge base and enabled them to realise that much work was needed to develop the knowledge base required for mathematics teaching. It is only when teachers (and prospective teachers) reach this conclusion themselves that will they be willing to invest the time and effort needed to extend and deepen their knowledge base.

In addition to appreciating the need to improve their own knowledge base students also acknowledged that the way they were taught may not have been the best way and admitted that they would now seek to deliver mathematics to their students in an improved manner. This indicates that this intervention could in fact help break the cycle of procedural teaching and learning. Much research conducted in the past has indicated that students worldwide prefer to be taught using a constructivist approach which promotes conceptual understanding (Nardi \& Steward, 2003) and students in this study were no different. They realised that teaching mathematics without ever explaining the background of the concepts, the links between different concepts or the applications of such concepts did not allow them to develop a deep understanding of mathematics. Subjects in this study were of the same opinion as Schoenfeld (1988) when he submitted that one of the main problems with procedural teaching was that it prevented meaningful learning from taking place in the classroom. Both the focus group responses and the evaluation sheets indicated that prospective teachers in this study now understood how sole emphasis on rote learning and procedural teaching in their past educational experiences had failed them in many regards and it was clear that they were now looking for alternative approaches for their own teaching. This adds substance to the arguments put forward by Stacey (2010) and Graeber (1999) who insist that it is critical to expose teachers to a variety of different teaching approaches in order to allow them to develop the skills necessary for effective mathematics teaching and to enable them to see the benefits and drawbacks associated with multiple different approaches to teaching.

Along with realising the limitations of their own knowledge bases and the need to move away from a procedural approach to teaching, prospective teachers and facilitators reported improved levels of conceptual knowledge among subjects in this study over the course of the intervention. Prospective teachers discussed how they had a new found confidence in their own ability and were finally beginning to understand the background and inter related nature of mathematics. In addition to this facilitators recorded a number of instances where students demonstrated conceptual understanding and a collateral knowledge of applications and connections towards the latter end of the study. This is something that the procedural approach to mathematics teaching favoured at second level does not allow for (Graeber, 1999). As a result this type of intervention allowed for students to develop the conceptual knowledge which has long been considered the missing domain in teachers' knowledge base and as advised by Monk (1991) it is now critical that teacher training courses continue to offer students means by which they can improve their understanding of mathematics prior to them entering the classroom. The question that now must be raised is how can this intervention inform future practices at third level and how, if at all, will it help break this cycle of procedural teaching? 


\section{Implications for Teacher Educators}

Teacher educators want teachers to teach differently, particularly now in Ireland with the introduction of Project Maths. We need prospective teachers to adopt a new set of teaching strategies that they may not have seen before. Kennedy (1999) tells us that teachers use frames of reference to inform their planning and classroom practice. By demanding a new type of teaching, we are asking teachers to change to a wholly different frame of reference. It involves changing their ideas about what teaching means, it means interpreting classroom situations differently and a complete reconsideration of how they might respond to these situations (Kennedy, 1999). This is very difficult to do Kennedy (1999) warns, particularly if students have been successful in terms of mathematics achievement at secondary level and third level thus far, they may regard this teaching as satisfactory as it worked for them and may not be interested in other ways of teaching (Toumasis, 1992). Hopper (1999) maintains that despite teacher education, newly qualified teachers relegate to traditional methods of teaching. Their experiences in primary and secondary give them ideas about what school subject matter is like, how students are supposed to act in school, and how teachers are supposed to act in school. Thus when they begin to teach, they adopt the practices of their former teachers (Kennedy, 1999). Even if they are critical of their own past teachers for teaching badly and for making them feel stupid, they may lack alternative models (Toumasis, 1992). To counter this Hopper (1999) recommends providing opportunities for prospective teachers to frame and reframe their conceptions of effective classroom practice.

One of the main benefits of this intervention was that it offered a new frame of reference for prospective teachers in this study and it is this finding that the researchers believe can help teacher educators when planning future teacher preparatory courses. To date students in this study had been exposed to rote learning and procedural teaching in the mathematics classroom. This course offered students an alternative approach to mathematics teaching. It promoted guided discovery, collaboration among peers, conceptual understanding and most importantly rules with reason. The findings from both the focus group and the evaluation sheets indicate that students appreciate this new frame of reference and value what it promotes. They believe that more modules at third level should be structured in this way and submit that only when mathematics is taught in this manner will people fully understand it and will the cycle of procedural teaching and learning be broken. Subjects in this study suggest that school mathematics needs to feature more prominently during teacher preparation courses and they need to be exposed to frames of reference that highlight how to deliver such content to second level students. This is in line with the findings of Ball (1990). The need for a variety of frames of reference has been discussed at length by Kennedy (1999) and the researchers believe that this intervention could offer one such frame of reference for future teacher training courses.

However the researchers accept that this is only one new frame of reference to which these prospective teachers have been exposed and it is of paramount importance that this frame of reference is worked on and that other frames are incorporated into future teacher training courses. Only then will teachers fully appreciate and see the benefits of moving away from the procedural approach to mathematics teaching.

It was disheartening to hear, however that despite exposing students to this new frame of reference, some prospective teachers felt it would easier to teach procedurally ('the wrong way') than conceptually ('the right way')

Marie: On Teaching practice even when you were out there even showing them why something is..like we'll say where did the distance formula come from? Using Pythagoras... they hated it. Like they hated it like. I know maybe they are a bit young but like they hated having to find out where it come... they were like' why can't you give us the formula? We'll just use it' 
It is evident that time constraints and students' resistance to change often lead to teachers reverting to procedural teaching. These prospective teachers concluded the focus group by stating that they would teach 'the right way' if they had a class of students from first year, but not if they took over a class from another teacher or took over a class close to examination time:

Gerard: Time constraints though would be another thing. It's almost like a balancing act between how much depth you go into some things... you do realistically have a curriculum to cover. You could spend a lot of time on them getting certain concepts and all that but you're maybe sacrificing the course is something I feel. It's probably the way the course is structured I suppose in some sense"

Aoife: I would have done it the wrong way....... s suppose if I started off maybe with first years I would have done it the right way but if I was doing it with some people that I thought they already knew what they were doing , I'd probably do it the wrong way. ... do you know?

Seamus: my experience of ...doing grinds with a lad doing ordinary level ... ...trying to explain to him, you know, why you are doing that ...it was kinda getting away from ... you know when you could be concentrating on him getting better marks for his leaving cert. He was in around the pass/ fail line so ...I felt...say from early on starting maybe with a 5th year class or starting with a first year class to do something like that ... at the stage they were at...trying to bring it all back to there and trying to work it up again ...you know it wasn't really appropriate for getting very good marks like for the exams. .....he was so used to the way he was doing it. If it was back at the start ...yeh definitely it probably would benefit people...since he was so used to doing it his own way... and then trying to change all his basic concepts of maths, it just wasn't appropriate at the time or anything.

Young teachers either completely forget their mathematical studies or try to connect their interpretation and treatment of the subject matter directly to their own school experience or they attempt to transfer the style of their own mathematical studies immediately into school practice. This leads to a vicious cycle which is reproduced continuously: bad secondary or university teacher $\rightarrow$ bad student $\rightarrow$ bad student teacher $\rightarrow$ bad secondary teacher and so on (Toumasis, 1992, p. 293). The intervention in this study was only 9 classes long which may not be enough to entirely convince prospective teachers to change to a new style of teaching.

The statements from the participants in this study and those of Toumasis above support the work of Hopper (1999) who states that despite the influence of teacher education programs, many beginning teachers maintain traditional, custodial practices in schools. He maintains that teacher education programs do not adequately equip prospective teachers to handle the demands of teaching. One of the issues here is that prospective teachers and teacher educators are highly likely to draw on different frames of reference on any discussion about teaching. Prospective teachers' practice is influenced by a frame of reference from their own schooling while teacher educators are likely to view the practice of teaching from a research perspective (Kennedy, 1999). Even if prospective teachers are critical of their own past teachers for teaching badly, it may be the only frame of reference they have to draw on (Toumasis, 1992). This, combined with a superficial level of mathematical knowledge, leads to a vicious circle of poor teaching that is very difficult to break.

To conclude the authors believe that interventions such as that discussed in this paper may be the first step needed at third level to break the cycle of procedural teaching which is affecting mathematics teaching worldwide. They do not submit that this is the only action that is needed to resolve the problem and instead they would encourage further research and initiatives are undertaken in this area to find further ways to help alleviate the problem. However the findings to emerge from this study do offer some hope. They suggest that providing students with a new frame of reference in this manner is beneficial as it allows them to experience alternative teaching strategies, 
analyse their own knowledge for teaching and most importantly in the context of this study reevaluate their beliefs in relation to effective mathematics teaching practices.

\section{References}

Ball, D.L., Hill, H.C. and Bass, H. (2005) Knowing Mathematics for Teaching: Who Knows Mathematics Well Enough to Teach Third Grade, and How Can We Decide. American Researcher, 29(1), 14 - 46.

Ball, D.L. (1990) The Mathematical Understandings that Pre-service Teachers bring to Teacher Education. Elementary School Journal, 90, $449-466$.

Behr, M.J., Khoury, H.A., Harel, G., Post, T. and Lesh, R. (1997) Conceptual Units Analysis of Preservice Elementary School Teachers' Strategies on a Rational Number as Operator Task. Journal for Research in Mathematics Education, 28(1), 48 - 69.

Boaler, J. (1998) Open and Closed Mathematics: Student Experiences and Understandings. Journal for Research in Mathematics Education, 29(1), $41-62$.

Britzman, D.P. (1991) Practice Makes Practice: A Critical Stuy of Learning to Teach. Albany, New York: SUNY

Brosnan, A. (2010) Project Maths Development Team: Supporting Good Practice. Presentation at the 24th Annual Meeting of the Irish Mathematical Society, University of Limerick, 29 August - 30 August 2011

Brousseau, G., (1984) The crucial role of the didactical contract. Proceedings of the TME 54.

Brousseau, G., (1997) Theory of Didactical situations in Mathematics. In A.J. Bishop (Ed.) Mathematics Education Library, Volume 19, Netherlands: Springer Netherlands.

Clarke, D. (2010) Speaking in and about mathematics classrooms internatinally: the technical vocabulary of students and teachers. Proceedings of Australian Council for Educational Research (ACER) Research Conference, 3-7.

Commission on the Points System. (1998) Consultative process - Background Document. Dublin, Ireland: The Stationary Office.

Conway, P. F. and Sloane, F. C. (2005) International Trends in Post-Primary Mathematics Education: Perspectives on Learning, Teaching and Assessment. Dublin, Ireland: National Council for Curriculum and Assessment.

Daro, P. (2010) Standards, What's the Difference? A View from Inside the Development of the Common Cord State Standards in the Ocassionally United States. Proceedings of Australian Council for Educational Research (ACER) Research Conference, $8-16$.

Crowther, K., Thompson, D. and Cullingford, C. (1997) Engineering degree students are deficient in mathematical expertiseWhy?. International Journal Of Mathematical Education in Science and Technology, 28(6), 785-792.

Da Ponte, J. P., \& Chapman, O. (2008). Preservice mathematics teachers' knowledge and development. In L. English (Ed.), Handbook of international research in mathematics education (2nd ed., pp. 225-263). New York, NY: Routledge.

Engineering Council (2000). Report on Measuring the Mathematics Problem. London, England: Engineering Council.

Ernest, P. (2010) The social outcomes of school mathematics: Standard, unintended or visionary?. Proceedings of Australian Council for Educational Research (ACER) Research Conference, 21 - 26.

Faulkner, F. (2012) An Analysis of Performance in Mathematics for Technology Undergraduates and an Investigation of Teaching Interventions for these Students. PhD thesis, University of Limerick, Unpublished.

Gill, O. (2006) What Counts as Service Mathematics? An Investigation into the 'Mathematics Problem' in Ireland. PhD thesis, University of Limerick, Unpublished

Gill, O., O'Donoghue, J., Hannigan, A., and Faulkner, F. (2010). Trends in Performance of Science and Technology Students (1997-2008) in Ireland. International Journal of Mathematical Education in Science and Technology, 41, 323-339.

Graeber, A. (1999) Forms of knowing mathematics: what preservice teachers should learm. Educational Studeis in Mathematics, 38, $189-208$.

Hopper, T. (1999) The Grid: reflecting from preservice teachers' experiences of being taught. The Journal of Physical Education, Recreation and Dance, 70(7), 53 - 59

Hourigan, M., and O'Donoghue, J. (2007). Mathematical under-preparedness: the influence of the pre-tertiary mathematics experience on students' ability to make a successful transition to tertiary level mathematics courses in Ireland. International Journal of Mathematical Education in Science and Technology, 38, 461-476.

Institute of Mathematics and its Applications (1995) Mathematics Matters in Engineering. Southend-on-Sea, UK: I.M.A.

Kennedy, M.K. (1999) The role of preservice teacher education, In Darling-Hammond and L Sykes (Eds). Teaching as the learning profession: Handbook of teaching and policy (pp. 54-86). San Francisco, USA: Jossey Bass.

London Mathematics Society (1995). Report on Tackling the Mathematics Problem. Southend-on-Sea, UK: L.M.S.

Lortie, D. (1975) Schoolteacher: A Sociological Study. London: University of Chicago Press.

Ma, L. (1999). Knowing and teaching elementary mathematics : teachers' understanding of fundamental mathematics in China and the United States. New York, USA: Routledge

Mirirai, C., Mutambara Lillias, H. N. and Chagwiza C.J, (2012) Teaching fractions at ordinary level: A case study of mathematics secondary school teachers in Zimbabwe. Educational Research and Review, 7(4), 90-101.

Monk, D.H. (1994) Subject Area Preparation of Secondary Mathematics and Science Teachers and Student Achievement. Economics of Education Review, 13(2), 125 - 145.

Murphy, M. (2002) An Investigation into the Mathematical Under-Preparedness Present Among Third Level Entrants: the Possible Contribution of the Second Level Mathematics Experience. PhD thesis, University of Limerick, Unpublished

Nardi, E. \& Steward,S. (2003) Is Mathematics T.I.R.E.D? A Profile of Quiet Disaffection in the Secondary Mathematics Classroom. British Educational Research Journal, 29(3), 345 - 366. 
Newton, K, Leonard, J., Evans, B. and Eastburn, J. (2012) Preservice Elementary Teachers' Mathematics Content Knowledge and Teacher Efficacy. School Science and Mathematics, 112(5), 289-299.

O'Donoghue, J. (1999). An intervention to assist at risk students in service mathematics courses at the University of Limerick. University of Limerick, Limerick: University of Limerick teaching fellowship scheme.

O' Meara, N., O'Donoghue, J. \& Gill, O. (2011) Improving Mathematics Teaching at Second Level through the Design of a Model of Teacher Knowledge and an Intervention Aimed at Developing Teachers' Knowledge. PhD thesis, University of Limerick, Unpublished.

Pegg, J. (2010) Promoting the acquisition of higher order skills and understandings in primary and secondary mathematics. Proceedings of Australian Council for Educational Research (ACER) Research Conference, 35 - 38.

Romberg, T.A., Carpenter, T.P. and Fennema, E. (1993) Towards a Common Research Perspective. In T. Romberg, E. Fennema \& T. Carpenter (Eds.) Integrating Research on the Graphical Representation of Functions (pp. 1 - 9), Hillsdale, New Jersey: Erlbaum

Sawx, G.B., Gearhart, M. and Nasir, N.S. (2001) Enhancing Students' Understadning of Mathematics: A Study of Three Contrasting Approaches to Professional Support. Journal of Mathematics Teacher Education, 4, 55 - 79.

Schoenfeld, A.H. (2009) Working with Schools: The story of a Mathematics Education Collaboration. The American Mathematical Monthly, 116, $197-217$.

Schoenfeld, A. H. (1988) When good teaching leads to bad results: The disasters of 'well-taught' mathematics courses. Educational Psychologist, 23(2), 145-166.

Schwartz, J. E. (2008) Elementary Mathematics Pedagogical Content Knowledge: Powerful Ideas for Teacher, New York, USA: Pearson.

Slattery, J. and Gill-Fitzmaurice, O. (2012) An Investigation into Preservice Teachers' Conceptual Knowledge of the Division of Fractions. Undergraduate Disertation Thesis, University of Limerick, Unpublished

Stacey, K. (2010) Mathematics teaching and learning to reach beyond the basics. Proceedings of Australian Council for Educational Research (ACER) Research Conference, 17 - 20.

Star, J.R. (2000) On the Relationship Between Knowing and Doing in Procedural Learning. Proceedings of Fourth International Conference of the Learning Sciences, 80-86.

State Examinations Commission (2001) Chief Examiner's Report (Ordinary Level Mathematics) http://www.examinations.ie/archive/examiners_reports/cer_2001/lcmaths_ol_01_er.pdf, (accessed June 2016)

State Examinations Commission (2005) Chief Examiner's Report, 2005. http://www.examinations.ie/archive/examiners_reports/cer_2005/LCMathematics.pdf (accessed June 2016)

Stylianides A.J. and Stylianides, G.J. (2007), Learning mathematics with understanding: A critical consideration of the learning principle in the Principals and Standards for School Mathematics. The Montana Mathematics Enthusiast, 4(1), 103-114.

Thompson, A.G. (1992) Teachers' Beliefs and Conceptions: A Synthesis of the Research. In D.A.Grouws (Ed) Handbook of Research on Mathematics Teaching and Learning (pp. 127 - 146). New York, USA : Macmillan.

TIMSS (1995). Third International Mathematics and Science Study. Boston: International Association for the Evaluation of Educational Achievement.

Toumasis, C. (1992) Problems in training secondary mathematics teachers: the Greek experience. International Journal of Mathematical Education in Science and Technology, 23(2), 287-299.

Yin R (1994) Case study research: Design and methods (2nd Ed.).Beverly Hills, CA: Sage Publishing. 